\title{
Foot Self-Care Positive Behaviorin Adults with Diabetes Following an Educational Intervention
}

\author{
Research Article
}

Luciana Catunda de Menezes Gomes ${ }^{1 *}$, Sherida Karanini Paz de Oliveira ${ }^{2}$, Deniziele de Jesus Moreira Moura ${ }^{1}$, Eline Saraiva Silveira Araújo ${ }^{2}$, Maria Vilani Cavalcante Guedes ${ }^{2}$

${ }^{1}$ Nursing Department, Fametro University Center, Fortaleza, Ceará, Brazil.

${ }^{2}$ Nursing Department, Ceará State University, Fortaleza, Ceará, Brazil.

\section{Abstract}

\begin{abstract}
Aim: The purpose of this study is to evaluate the effect of an educational intervention on the foot self-care behavior in patients with diabetes.

Method: Aquasi-experimental study was carried out with 40 patients with diabetes, from a Primary Healthcare Center in Fortaleza, Ceará, Brazil. An educational nursing intervention for the prevention of diabetic foot was used and patients underwent evaluations (dermatological, orthopedic, circulatory, and neurological) following the intervention. The McNemar test was used to evaluate the effect of the intervention.

Results: After the intervention, $62.5 \%$ of thepatients started wearing shoes at all times, $32.5 \%$ started hydrating their feet daily, and only $2.5 \%$ started wearing appropriate shoes. The dermatologicalevaluation showed that the intervention had a positive effect in reducingexposure to risk factors $(\mathrm{p}<0.001)$, as patients started to correctly use instruments for the proper cutting of nails and showed reduced skin dryness and cracks.

Conclusion: The educational intervention was effective to cause increasein the knowledge and acquisition of foot self-care positive behavior in patients with diabetes.
\end{abstract}

Keywords: Nursing; Nursing Care; Diabetic Foot; Diabetes.

\section{Introduction}

The increasing number of people with diabetes mellitus (DM) in Brazil and worldwide has prompted professionals to develop different strategies to prevent andcontrol the disease. The consequences of DM are substantial and includes microvascular complications such as neuropathy, which causes loss of sensation, repetitive superficial deformities and traumas, skin cracks, and damage to the feet, often not noticed by the patient [1].

Diabetic neuropathy has a chronic evolution and affects, especially, the lower limbs. This complication appears, on average, ten years after the onset of diabetes and, when associated with ischemia and infection, it can be aggravated with unpredictable speed, leading to the appearance of the diabetic foot and amputation of the lower limbs [2].
As pointed out by scholars, $75 \%$ of the population with DM will manifest neuropathy at some point in their life, which can reach up to $100 \%$ in people with poorly controlled diabetes. As a consequence, many of these patients will develop diabetic foot syndrome, a serious chronic, mutilating, and recurring complication, with high costs for the individual and the health system $[1,3]$.

It is estimated that $25 \%$ of the patients with diabetes have diabetic foot, and $85 \%$ of these injuries lead to amputations. Every minute, two amputations occur worldwide due to DM [4], and, in Brazil, approximately 40,000 amputations occur per year [5].

By knowing the causes of diabetic foot, patients at high risk can be identified early and, thus, complications can be avoided. In this context, the assessment of the degree of risk in addition to the encouragement of self-care, interdisciplinary care, and health education can reduce the occurrence of injuries by up to $50 \%$ [6].

*Corresponding Author:

Luciana Catunda de Menezes Gomes,

Nursing Department.Fametro University Center, Fortaleza, Ceará, 60010-260, Brazil.

Tel: 5585 99171-7971

E-mail: dra.lucianacatunda@yahoo.com/deniziellemoreira@gmail.com

Received: July 17, 2020

Accepted: August 10, 2020

Published: August 12,2020

Citation: Luciana Catunda de Menezes Gomes, Sherida Karanini Paz de Oliveira, Deniziele de Jesus Moreira Moura, Eline Saraiva Silveira Araújo, Maria Vilani Cavalcante Guedes. Foot Self-Care Positive Behaviorin Adults with Diabetes Following an Educational Intervention. Int J Diabetol Vasc Dis Res. 2020;8(1):261-265. doi: http://dx.doi.org/10.19070/2328-353X-2000049

Copyright: Luciana Catunda de Menezes Gomes ${ }^{\circ}$ 2020. This is an open-access article distributed under the terms of the Creative Commons Attribution License, which permit unrestricted use, distribution and reproduction in any medium, provided the original author and source are credited. 
Health education for these patients consists of a process that facilitates knowledge and skills, involving practices of physical exercises, diet, therapy, feet examination, care for wounds, and other actions performed by the patient himself. These initiatives are aimed at an effective metabolic control, a better quality of life with more accessible costs, and a constant self-surveillance by the patients $[7,8]$.

The World Health Organization (WHO) recommends the use, in health institutions, of educational activities that excel in the generation of knowledge, autonomy, and management capacity of the individuals regarding their disease [9]. There is still no standardization of educational actions aimed at people with diabetes, but they should aim to raise awareness and warn about self-care and generate a greater focus for those who are at risk for diabetes related injuries.

It is important to develop patients' critical thinking and an active construction of new knowledge. Research on the effect of educational interventions aimed at the self-care of diabetic patients can generate subsidies for a better clinical evaluation of the feet and contribute to the improvement of the quality of life of this population. Thus, this study aims to evaluate the effect of an educational intervention on the foot self-care behavior in patients with diabetes.

The study questions are as follows: (1) What is the foot self-care behavior of patients with diabetes before and after an educational intervention? (2) Is there a difference in the foot self-care behavior of patients with diabetes before and after educational intervention?

\section{Method}

The research was approved by the ethics committee of the CearáState University under opinion No. 1235019 (CAAE No.47663215.5.0000.5534). All participants signed a written informed consent prior to participation, respecting the ethical precepts of research with human beings based on the Brazilian Resolution 466/12 of the National Health Council [11].

\section{Study design and location}

A quasi experimental before-and-after study was developed to test an educational intervention. The intervention consisted in usingpamphlets, anatomical models of feet with and without lesions, and a bookletto teach patients with DM about foot care.

The study was carried out in a Primary Healthcare center located in Fortaleza, Ceará, Brazil.

\section{Sample}

A convenience sample of 40 people with DM, of both sexes, and registered in the hypertension and diabetes program of the primary healthcare center was recruited.

The study included patients who met the following criteria: having a medical diagnosis of type 2 DM for at least three years, since diabetic foot develops in the chronic phase of the disease; be over 18 years old; and being under monitoring by a health team from the selected healthcare center at the time of data collection. Those with cognitive impairment and who had limitations that could compromise their communication were excluded.

\section{Study protocol}

The first meeting with the study participants consisted in filling out a survey of the needs for guidance on self-care, and a diabetic foot risk assessment. At this meeting, the peripheral pulses (dorsalis pedisand posterior tibial) were palpated, and the tactilepressure and vibratory sensitivities were tested. Patients were asked to communicate the absence or presence of sensitivity in the palpated sites of the lower limbs.

The dorsalis pedis and posterior tibial pulses were examined by the palpatory method and classified as palpable or non-palpable. All evaluations were carried out in accordance with the recommendations of the International Working Group on Diabetic Foot (IWGDF) [1].

The pressure sensitivity was tested using a Semmes-Weinstein 5.07/10 g monofilament, at three sites (first metatarsal head and first and fifth digits). The presence of diabetic neuropathy was defined as three wrong answers. Following the recommendations of the International consensus, responses were recorded as they were said by patients, for example: "I felt a sting", or"a nip", among others.

To check vibratory sensitivity, a $128-\mathrm{Hz}$ tuning fork was used at three sites on each foot: medial malleolus, hallux proximal phalanx and foot dorsum. Sensitivity was considered compromised when there was a lack of sensitivity in one of the three points used for the test, after three consecutive attempts [1].

The tests generated information for the diabetic foot risk assessment, classified according to the presence of the following risk factors: diabetic neuropathy, peripheral vascular disease, foot deformities and history of previous ulcer. These factors were graded from 0 to 3 , according to their absence or presence.

After this initial evaluation, an educational intervention was carried out with a focus on the foot self-care behaviors.

The educational intervention was based on guidelines for foot self-care aimed at preventing and managing complications of the diabetic foot. Pamphlets, anatomical models of feet with and without lesions, and a booklet [11] were used, since these materials could facilitate the interaction between patients with the topic and facilitate the understanding of related information about foot care.

The booklet, whose Content Validity Index (CVI) is 0.99 , is called "A Healthy Foot is a Well-Cared Foot", has 40 pages,150x200mm in size, and is printed in orange and blue. The content was summarized in topics, namely: What is diabetic foot? How to prevent diabetic foot? How should I take care of my feet? Where should I seek help? [11].

Three months after the first evaluation and educational intervention, patients underwent a new evaluation of the tactile pressure and vibratory sensitivities for comparison. 
The meetings lasted thirty minutes and took place individually, with the presence of a family member or companion, since these people provide support for the patients to deal with the diabetes.

\section{Variables}

The data collection instrument was divided in three parts. The first part included sociodemographic and clinical variables (gender, age, time of diagnosis, current treatments, capillary blood glucose, diabetic foot knowledge, comorbidities, and risk factors). The second included variables related to foot care (washing, drying, hydration, nail cutting, type of shoes and socks used by the patient, examination of the feet, and wound care). Finally, the third part addressed the variables associated with dermatological, circulatory, orthopedic and neurological evaluations of the feet.

\section{Data analysis}

Data were inserted in an Excel (version 2010) spreadsheet and analyzed using SPSS (version 20.0, license No. 10101113007). Sociodemographic variables were analyzed as well as the variables from the clinical, dermatological, circulatory, orthopedic, and neurological evaluation, in addition to the foot care variables obtained with the patients. The McNemar test was used to compare the variables before and after the intervention, using a significance value of $\mathrm{p}<0.005$.

Data were inserted in an Excel (version 2010) spreadsheet and analyzed using SPSS (version 20.0, license No. 10101113007). Sociodemographic variables were analyzed as well as the variables from the clinical, dermatological, circulatory, orthopedic, and neurological evaluation, in addition to the foot care variables obtained with the patients. The McNemar test was used to compare the variables before and after the intervention, using asignificance value of $\mathrm{p}<0.005$.

\section{Results}

\section{Sociodemographic and clinical characterization}

The sample was predominantly female $(62.5 \%)$. The age ranged from 32 to 90 years, with an average of $58.6 \pm 11.7$ years. An average of $8.9 \pm 7.0$ years of diagnosis was found, showing that most patients had the disease for long enough to develop complications. The prevalence of risk factors was as follows: $70.0 \%$ had arterial hypertension, $72.5 \%$ had overweight or obesity, $22.5 \%$ were smokers, and $35.0 \%$ had a family history of DM.

The degree of risk was assessed before and after the educational intervention. It was observed that $42.5 \%$ had risk grade $0,25.0 \%$ had riskgrade $1,17.5 \%$ had risk grade 2 , and $15.0 \%$ had risk grade 3. This graduation did not change during the research period, perhaps, due to the fact that the study was developed in three months.

In the dermatological evaluation, the variables improper nail cutting, dryness, and cracks changed significantly from the first to the second evaluation $(\mathrm{p}<0.05)$. This indicates that the guidelines and self-care demonstrations reduced the occurrence of risk factors in the sample (Table 1).

Correct cutting of nails is essential to prevent injuries. In this study, $65 \%$ of the patients used to cut their nails in a round shape. After the intervention, this number decreased to $47.5 \%$ witha statistically significant difference $(\mathrm{p}=0.001)$.

Regarding dryness, $60 \%$ of the patients had dry feet before the intervention, and only $40 \%$ still had dry feet after the intervention, with a statistically significant difference $(\mathrm{p}=0.0012)$.

Table 1. Distribution of data from the patients' evaluations before and after the educational intervention.

\begin{tabular}{|c|c|c|c|c|c|}
\hline \multirow{2}{*}{ Variables } & \multicolumn{2}{|c|}{ Before } & \multicolumn{2}{c|}{ After } & \multirow{2}{*}{ p value* } \\
\cline { 2 - 5 } & $\mathbf{f}$ & $\mathbf{0}$ & $\mathbf{f}$ & $\mathbf{0}$ & \\
\hline Dermatologicalevaluation & & & & & \\
\hline Impropernailcutting & 26 & 65 & 19 & 47.5 & 0.001 \\
\hline Dryness & 24 & 60 & 16 & 40 & 0.012 \\
\hline Skin cracks & 19 & 47.5 & 11 & 27.5 & 0.001 \\
\hline Circulatoryevaluation & & & & & \\
\hline Edema & 12 & 32 & 12 & 32 & - \\
\hline Intermittentclaudication & 1 & 2.5 & - & - & - \\
\hline Orthopedicevaluation & & & & & \\
\hline Clawingofthe toes & 4 & 10 & 4 & 10 & - \\
\hline Caved-in foot & 3 & 7.5 & 3 & 7.5 & - \\
\hline Hammertoe & 2 & 5 & 2 & 5 & - \\
\hline Charcotfoot & 2 & 5 & 2 & 5 & - \\
\hline Neurologicalevaluation & & & & & \\
\hline Formication & 19 & 47.5 & 19 & 47.5 & - \\
\hline Numbness & 18 & 45 & 18 & 45 & - \\
\hline Tingling & 7 & 17.5 & 7 & 17.5 & - \\
\hline Heatsensation & 5 & 12.5 & 5 & 12.5 & - \\
\hline
\end{tabular}

* McNemar test. 
Regarding skin cracks, a total of $47.5 \%$ of the participants had this problem before the intervention. The intervention provided information about the increased risk of foot ulcers in people with this problem. As a result, at the end of the study, only $27.5 \%$ of the participants still had skin cracks, with a significant $\mathrm{p}$ value $(\mathrm{p}=0.001)$.

There were no changes in circulatory, orthopedic, and neurological evaluations after the educational intervention, which can be justified by the fact that the research took place in just three months. In addition, these are chronic changes of DM.

It should be noted that the data obtained in the study are worrisome, especially since few participants had the habit of examining their feet daily. Reasons include:unknown of the existence of a problem with the feet, lack of belief in the need for feet care, lack of time, difficulties related to advanced age, visual impairment, lack of family support, and absence of a trained professional to perform a proper examination.

\section{Discussion}

The sociodemographic characteristics found in this research were similar to those reported in otherBrazilian studies with patients with diabetes $[12,13]$. The time of diagnosis found in the sample isclassified as critical for the onset of diabetic neuropathy [1]. Studies have shown thatmany patients are diagnosed with diabetes at the same time that they are being treated for diabetes-related complications [14]. Thus, evidence of micro and macrovascular complications may appear after the patient progresses with undetectable hyperglycemia (for approximately four to seven years). This, in addition to increasing age, accentuates the severity of vascular complications, including ulcers [11].

Self-management education is animportant strategy for patients with diabetes to achieve goals that are essential for the metabolic control, to prevent acute and chronic complications, to improve the patients' quality of life, and to reduce costs [15]. All health education modalities are effective in promoting the patients' self-care. However, in regards to foot self-care, group strategies and interventions have shown greater effectiveness, enabling improved knowledge and care in addition to adherence to treatment and diet [16].

The findings related to the foot evaluation variables before and after the educational intervention showed that patients significantly improved in regards tonail cutting, and skin hydration (with a decrease in the number of patients with skin dryness and cracks).

The importance of educational practices for people with diabetes mellitus has been discussed in other study as an effective method that generates countless benefits for patients and professionals, mainly through the construction of a conscious self-care and achievement of metabolic control. Therefore, such practices contributes to improving the quality of life [17].

Thus, it can be inferred that the educational intervention provided in this study favored the adoption of better self-care practices among the participants, especially regarding the proper cutting of nails and skin hydration.
Patients with diabetes must be instructed about how to properly cut their nails, as follows: nails have to be cut in square shape, straightly and horizontally, using pliers; nail tips must be sand but not extremely short; nail corners must not be cut; and ingrown nails must be cut only by a specialized podiatrist [1].

It is important to mention that the family participation in the educational process is of great value, as family provides a support network that enhances the effects of any educational intervention, and contributes to the identification of risk factors for footulcers $[5,18]$.

Regarding hydration, the recommendations are that patients with diabetes must hydrate ther feet regularly, preferably three times a day, with urea-based cream in the plantar, dorsal and heel regions, except between the interdigital spaces to avoid fungal infection [1].

It was observed that must study participants did not have the habit of hydrating their feet at the first evaluation. However, positive results were obtained after the intervention, with improvement in dryness and cracked feet.

Similar results were found in a quasi-experimental study in which many participants had dry skin and cracks. The intervention tested by the authors was also effective in improving these conditions [19]. Cracks and dryness in patients are triggered by the impairment of sensitive, motor and autonomic fibers, resulting in a reduction in the supply of sweat [1].

Patients with diabetes are responsible for about $95 \%$ of their care. Thus, actions aimed at foot care are the best strategy to delay or decrease complications such as diabetic foot [11].

A study carried out in health centers in the city of San Luís Potosí, Mexico, described the sociodemographic and clinical profile of people with diabetes and their foot care habits before and after an educational intervention. Authors used participatory and traditional communication and have found that knowledge about foot care among individuals with diabetes contributes to avoid future complications [19].

A systematic review evaluated 11 studies (5 randomized clinical trials and 6 quasi-experimental studies).From these studies, two clinical trials were effective in reducing cardiovascular complications, cataracts, retinopathy, and nephropathy in patients,and all quasi-experimental studies showed effectiveness in reducing foot ulcers, peripheral vasculopathy, neuropathy, and in maintaining the patients' renal function [20].

An educational intervention performed by nurses was effective in reducing mild foot problems after three months of follow-up, such as: calluses: $57.1 \%$ versus $44.1 \%(p=0.089)$; cracks: $28.6 \%$ versus $0(p=0.000)$; redness: $17.9 \%$ versus $0(p=0.001)$; heel fissures: $17.9 \%$ versus $3.6 \%(\mathrm{p}=0.219)$; blisters: $1.8 \%$ versus 0 $(p=0.500)$; fungal infection: $3.6 \%$ versus $0(p=0.248)$; adequate hygiene: $80.4 \%$ versus $100 \%(\mathrm{p}=0.000)$; adequate nail length: $76.8 \%$ versus $94.6 \%(p=0.007)$; and normal thickness: $80.4 \%$ versus $94.6 \%(\mathrm{p}=0.022)[21]$.

In the present study, the use of images and simple technologies, 
such as a booklet, pamphlets, and an anatomical model of the feetto illustrate and simulate the guidelines, produced satisfactory results. Such instruments facilitate the teaching and learning process and stimulate patients to reflect and decide on the adoption of healthier habits.

The management of diabetes should include, among other aspects, educational actions aimed at preventing complications. Many patients lack information and seek for health services only when foot injuries appear. The educational intervention carried out in this study favored the adoption of habits to prevent diabetic foot complications, favoring positive behaviors related to foot care.

\section{Study Limitations}

The short follow-up period was the main limitation of this study, as many injuries only appears after a long period after the diabetesdiagnosis. There is a need for longer studies that classify and evaluate the diabetic foot as part of the nursing practices. Such studies can improve the quality of life of people with diabetes and prevent complications. In addition, the reduced sample size can be considered as a limitation.

\section{Implications/Relevance for clinical practice}

This study has implications for health educators and nurses who provide care for patients with diabetes, as it provides subsidies for the planning of effective educational interventions aimed at the foot self-care. As evidenced in the research, the effectiveness of educational strategies is evident, which can be reproduced, improved or reinvented by other health professionals. Health workers, especially nurses (who are considered to be genuine health educators), should institute creative and emancipatory practices with patients at any level of care, according to the needs of the community.

\section{Conclusion}

The educational intervention developed in this study, for patients with diabetes mellitus from a primary healthcare center, consisted in pamphlets, anatomical models of feet with and without lesions, and a booklet. The intervention resulted in a significant increase in the adoption of foot self-care positive behaviors. Specifically, statistically significant differences between the pre and post-intervention were found in regards to nail cutting, presence of skin dryness, and skin cracks.

\section{Acknowledgement \& Declarations}

The authors declare no conflicts of interest.

This study received funding from the Ceará State Foundation for Scientific and Technological Development (FUNCAP).

\section{References}

[1]. Guías del IWGDF para la prevención y el manejo de la enfermedad de pie diabético IWGDF. Amsterdam: International Working Group on the Diabetic Foot; 2019. Available from: http://www.iwgdfguidelines.org

[2]. Papanas N, Maltezos E. Polyherbal formulation as a therapeutic option to improve wound healing in the diabetic foot. Indian. J Med Rev. 2011;
134(2): 146-7. PMID: 21911965.

[3]. Pedrosa HC, Vilar L, Boulton AJ. Neuropathies and diabetic foot. Pharmaceutical AC; 2014

[4]. Tesfaye S, Selvarajah D. Advances in the epidemiology, pathogenesis and management of diabetic peripheral neuropathy. Diabetes Metab. Res. Rev. 2012; 28(3): 8-14. PMID: 22271716.

[5]. Audi EG, Moreira RC, Moreira ACMG, Pinheiro EFC, Mantovani MF, Araújo AG. Foot evaluation and risk classification for diabetic foot: nursing contributions. CogitareEnferm. 2011; 16(2): 240-246.

[6]. da Silva JM, Haddad MD, Rossaneis MA, Marcon SS. Ulceration risk in diabetic feet: a cross-sectional study. Online Brazilian Journal of Nursing. 2015; 14(3): 229-37.

[7]. Funnell MM, Brown TL, Childs BP, Haas LB, Hosey GM, Jensen B, et al. National standards for diabetes self management education. Diabetes Care. 2011; 34 (Suppl 1): S89-S96. PMID: 21193633.

[8]. Chaves MO, Teixeira MRF, Silva SED. Perceptions of people with diabetes about the disease: nursing contributions. Rev Bras Enferm. 2013; 66(2): 215-221.

[9]. Nascimento EA, Tarcia RML, Magalhães LP, Soares MAL, Suriano MLF, De Domenico EBL. Educational pamphlets on health: a reception study. Rev Esc Enferm USP. 2015; 49(3): 435-442.

[10]. Brazil. Ministry of Health. Health Council Resolution. Guidelines and standards regulating researches involving human beings. 2012.

[11]. Galdino YLS, Moreira TMM, Marques ADB, Silva FAA. Validation of a booklet on self-care with the diabetic foot. Rev. Bras. Enferm. 2019; 72(3): 780-787. PMID: 31269146.

[12]. Brazilian Diabetes Society. Brazilian Diabetes Society Guidelines 20192020. (7 edtn). Clannad, 2019.

[13]. Lyra R, Silva RS, Montenegro Jr. RM, Matos MVC, Cézar NJB, Silva LM. Prevalence of diabetes and associated factors in an urban adult population of low educational level and income from the Brazilian Northeast wilderness. Arq. Bras. Endocrinol. Metab. 2010; 54(6): 560-566. PMID: 20857062.

[14]. Cortez DN, Reis IA, Souza DA, Macedo MM, Torres HC. Complications and the time of diagnosis of diabetes mellitus in primary care. Acta Paul Enferm. 2015; 28(3): 250-255.

[15]. Iquize RCC, Theodoro FCE, Carvalho KA, Oliveira MA, Barros JF, Silva AR. Educational practices in diabetic patient and perspective of health professional: a systematic review. J Bras Nefrol. 2017; 39(2): 196-204. PMID: 29069244.

[16]. Menezes LCG, Guedes MVC, Moura NS, Oliveira RM, Vieira LA, Barros AA. Educational strategies for diabetic people at risk for foot neuropathy: synthesis of good evidence. Rev. Eletr. Enf. 2016; 18: 1197-1195.

[17]. Borba AKOT, Marques APO, Leal MCC, Ramos RSPS. Educational practices for diabetes Mellitus: integrative literature review. Rev Gaúcha Enferm. 2012; 33(1): 169-176. PMID: 22737810.

[18]. Martin VT, Rodrigues CDS, Cesarino CB. Conhecimento do paciente com diabetes mellitus sobre o cuidado com os pés. Rev enferm UERJ. 2011; 19(4):621-5.

[19]. Rodríguez P, Godoy MC, Mazzo S, Nogueira A, Trevizan PC, Mendes MA. et al. Diabetic foot care before and after an educative intervention. Enfermería Global. 2013; 29(1): 53-62.

[20]. Menezes MM, Lopes CT, Nogueira LS. Impact of educational interventions in reducing diabetic complications: a systematic review. Rev Bras Enferm. 2016; 69(4): 773-84. PMID: 27508485.

[21]. Fan L, Sidani S, Cooper-Brathwaite A, Metcalfe K. Feasi- bility, acceptability and effects of a foot self-care educational intervention on minor foot problems in adult patients with diabetes at low risk for foot ulceration: a pilot study. Can J Diabetes. 2013; 37(3): 195-201. PMID: 24070843. 